\title{
Formação continuada de professores(as) e sua relação com o conceito de acontecimento
}

\author{
Elisabete Andrade ${ }^{1}$ \\ Arnaldo Nogaro ${ }^{2}$ \\ Helena Copetti Calai ${ }^{3}$
}

\section{Resumo}

O texto parte do entendimento de que a formação continuada e o desenvolvimento profissional de professores são espaços-tempo de estudos e de reflexões que acontecem ao longo da carreira docente e que, dependendo da maneira como são organizados, podem possibilitar o aprofundamento teórico-conceitual acerca de determinadas disciplinas ou áreas do conhecimento, estarem diretamente relacionados a temáticas que estejam vinculadas à prática pedagógica que o(a) professor(a) desenvolve no interior das salas de aula ou, ainda, discutirem temas que versem sobre a educação numa perspectiva mais global. A partir da investigação bibliográfica, analisa-se como os processos de formação continuada de professores, operando a partir da lógica apresentada com o conceito de acontecimento, pode abrir espaçostempo de formação que potencializem os sujeitos-professores a se desenvolverem profissionalmente. Essa perspectiva analítica pode conduzir a outros modos de se pensar os processos formativos de professores, vislumbrando a possibilidade de constituição de uma estética do cotidiano.

Palavras-chave: Formação continuada de professores. Acontecimento. Estética do cotidiano.

1 Doutora em Educação nas Ciências - Unijuí.

2 Doutor em Educação - UFRGS.

3 Doutora em Geografia - USP. 


\title{
Continuing education teachers and its relationship with the event concept
}

\begin{abstract}
The following abstract is based on the presumption that professional educators continue learning and developing their skills - both in and out of the classroom as they complete their degree at university, as well as during their professional careers as an educator. To be certain, these experiences help them to acquire a deeper knowledge on both the conceptual and rhetorical sides in certain fields of study; and depending on how this information is organized, it can lead to a deeper understanding of theoretical and conceptual concepts in disparate fields of study. These experiences may be connected to a certain field or pedagogic practice which educators develop in class, or they may be integrated into different themes related to education on a global scale. If we look at the number of books on the topic, we can see how combining the process of formal training at the university level, with planned in-service sessions for educators at all levels, works to provide educators with new and innovative skills sets that will allow them to maximize their teaching potential. This perspective will create a paradigm shift which educators can then use to create a new, daily, aesthetic outlook in their classrooms [at all levels of teaching].
\end{abstract}

Keywords: Continuing education of teachers. Event. Everyday aesthetics.

\section{Introdução}

A formação continuada de professores é uma temática recorrente nas pesquisas da área de educação. A cada novo estudo e a cada nova análise acerca desses processos formativos, avançamos em entendimentos e em produção acadêmica. As possibilidades de estudos não se esgotam, ainda mais se considerando alguns distanciamentos e até incoerências no campo da prática pedagógica. Na superfície das análises de que 
trata este texto, está justamente o contexto das práticas pedagógicas desenvolvidas na Educação Básica. Essa é uma preocupação relevante que atinge diretamente os processos de formação inicial e continuada de professores, por isso, a partir da pesquisa, tenta-se dialogar para se entender as condições e as possibilidades de desenvolvimento de um processo de formação que possa vir a transformar os modos de ser professor(a) e, dessa forma, qualificar as formas de ensinar e de aprender.

Por mais esforços que tenham sido feitos nos últimos vinte anos, a formação continuada pode não estar conseguindo suprimir as necessidades formativas dos professores(as), principalmente no que diz respeito aos aspectos teórico-conceituais. São feitos investimentos por parte dos governos e das autarquias (federal, estadual e municipal), porém, ainda não conseguem garantir, na formação continuada, a produção de conhecimentos com a profundidade e a complexidade necessárias para se exercer a docência com a qualidade almejada. Essa problemática tem gerado a inércia e certa desconfiança por parte dos docentes, o que, consequentemente, pode gerar a estagnação das mudanças desejadas pela maioria das pessoas que se dedicam aos interesses da educação.

As contribuições deste texto consideram a necessidade de se produzir uma cultura formativa em que os docentes se sintam e sejam vistos socialmente como intelectuais que, para além de dominarem técnicas sobre como ensinar, também tenham condições de pensar criticamente sobre tais práticas e tais técnicas, produzindo continuamente, de forma autônoma, responsável e ética, sua formação e sua profissão. Reconhecendo que, para isso, é necessário priorizar uma estrutura política e institucional que garanta essa possibilidade. Em outras palavras, há a necessidade de se instaurar processos formativos que provoquem atitudes reflexivas que resultem na construção de si mesmo e de sua identidade profissional. "Nesse sentido, o sujeito quando reflexivo pode ressignificar o mundo onde vive e, a partir de suas experiências e relações com ele, promover conhecimentos capazes de transformar e contribuir para a construção de si mesmo chegando a ser sujeito e não um 'asujeitado" (NOGARO; SILVA, 2015). 
Tem sido comum entender a formação continuada de professores apenas como eventos dos quais os docentes participam ora como ouvintes de palestras, de conferências, de seminários, de oficinas, ora como pesquisadores que socializam seus estudos. Além desse modelo de formação continuada, há os processos que podem ser denominados como acadêmicos, o caso da pós-graduação, tanto latu quanto stricto sensu, um formato focado na pesquisa e na produção acadêmica. Ressaltamse a relevância e a necessidade desses espaços coletivos amplos denominados e reconhecidos com formação continuada de professores. Porém, queremos pensar a formação continuada de professores no "entretempo" em que a docência acontece. O movimento do pensar a formação continuada de professores que sustenta as análises propostas neste texto considera a necessidade de desenvolvimento de um olhar sensível aos dizeres e fazeres do cotidiano, espaço que também tem importante caráter formativo.

Corroboramos a ideia de que, no processo de formação, "o ensino não pode ser inflexível” (GIRALDI, 2010, p. 100). Estar atento ao que acontece, desenvolvendo a capacidade de fazer perguntas e de se sensibilizar por obviedades do cotidiano e, com elas, aprender e se desenvolver profissionalmente, não se opõe à seriedade e à responsabilidade que é peculiar a esse processo, porque "admitir a variedade não é admitir o espontaneísmo" (GIRALDI, 2010, p. 101). A educação e a formação de professores(as), bem como a formação continuada de professores(as), problemática deste texto, tem seguido padrões prescritivos que se movimentam no intuito de universalizar os processos formativos e, como consequência, generalizar também as condutas docentes.

Tendo por base o conceito de acontecimento desenvolvido especialmente por Deleuze (DELEUZE; GUATTARI, 2011), e também a partir da teorização feita por Foucault na obra O Governo de Si e dos Outros (2010), entende-se ser possível problematizar outras maneiras de se compreender o processo formativo, em especial a formação continuada de professores(as). É necessário, porém, deixar-se afetar e se sensibilizar com o que acontece no momento mesmo em que acontece, seja na forma de eventos menos formais ou mais formalizados e prescritivos. Em ambos 
os casos, é importante considerar o desenvolvimento de um olhar crítico e sensível acerca do que acontece e de como esses acontecimentos afetam os(as) docentes. A ideia é a de que os acontecimentos possam constituirse em experiências formativas. Assim, os docentes, movidos por um interesse sensível, têm condições de aprender mais sobre sua prática pedagógica, sobre os seus alunos, sobre a sua vida e sobre sua própria condição de professor-sujeito.

\section{Adentrando no conceito de acontecimento}

Acontecimento é um conceito que tem sido pouco aprofundado na área da educação, menos ainda na formação de professores, seja inicial ou continuada. Existem, porém, alguns pesquisadores brasileiros, como Giraldi (2010), Gallo (2007), Kohan (2002), Silva e Corazza (2004) e Corazza (2007a, 2007b), que têm se dedicado, com base nos estudos de Deleuze, a pensar esse conceito e a relacioná-lo às temáticas que envolvem a educação e a formação de professores(as). Para Corazza: “Na relação amorosa com os conceitos deleuzianos, distingo um deles que me parece imprescindível para a pesquisa contemporânea em Educação: o de acontecimento" (CORAZZA, 2007b, p. 68).

Conforme Corazza (2007b), o conceito de acontecimento é formulado ao longo de toda a produção de Deleuze, desde a sua tese de estado diferença e repetição - na qual tanto o problema quanto suas condições são remetidos à ordem do acontecimento - até ganhar força e complexidade em Lógica do sentido - sob a influência da teoria estoica dos incorporais e de Leibniz - passando pelo livro A dobra. Leibniz e o Barroco - em que há um capítulo inteiro dedicado à questão "Que é acontecimento?" e no qual Whitehead é identificado como o terceiro pensador do acontecimento - indo até o último livro escrito com Guattari O que é filosofia? - em que aparecem como influências Péguy e Blanchot, saudados como os novos pensadores que foram capazes de penetrar o acontecimento - chegando até seu último texto "A imanência: uma vida...", em que escreve: "Uma vida [...] é feita de virtualidades, acontecimentos, singularidades. Os acontecimentos ou singularidades dão ao plano toda sua virtualidade, 
como o plano da imanência dá aos acontecimentos virtuais uma realidade plena" (CORAZZA, 2007b).

A temática da formação continuada de professores(as) problematizada neste texto encontra-se com Deleuze por entender que o conceito de acontecimento potencializa o devir formativo. Devir é nunca imitar, nem fazer como, nem se conformar a um modelo, seja de justiça ou de verdade. À medida que alguém se transforma, aquilo em que ele se transforma muda tanto quanto ele próprio. Os devires não são fenômenos de imitação, nem de assimilação, mas de dupla captura, de evolução não paralela (ZOURABICHVILI, 2004). A formação continuada de professores pode ser pensada nessa perspectiva, pois é algo que acontece no e com o próprio sujeito, este sendo capturado ou não pelas aprendizagens decorrentes do processo. A formação continuada de professores baseada apenas na transmissão de modelos e fórmulas pode dar alguns parâmetros que ajudem os professores(as) a pensarem, mas que, por si só, não são formativos. É necessário refletir sobre eles, articular com os contextos, encontrar-se com a vida das pessoas, pois, caso contrário, acaba sendo superficial, muito próxima do "treinamento", incentivando reações padronizadas, pouco recomendadas para quem trabalha educando pessoas "[...] que exercem funções pautadas pelo uso da inteligência e nunca apenas pelo uso de seus olhos, seus passos ou seus gestos" (MARIN, 1995, p. 15).

Como afirma Deleuze, "encontrar é achar, capturar, roubar, e roubar é o contrário de plagiar, copiar ou fazer como" (KOHAN, 2002, p. 130). A ideia é de que a formação continuada de professores possa promover tais encontros, que abram espaços para a captura daquilo que nem sempre pode ser controlado, medido, cronometrado, mas que simplesmente acontece quando se deixa em aberto as possibilidades interpretativas do mundo e da vida. Por isso, tomo o conceito de acontecimento para pensar a formação continuada de professores (FCP) de um lugar diferente daquele pelo qual tem sido nomeada, e, por vezes, enquadrada por roteiros pré-definidos e planejamentos enrijecidos. Relacionar o acontecimento à formação continuada de professores sugere a abertura de espaço para pensar, de forma singular, o processo de produção do conhecimento que 
atravessa os sujeitos-professores(as), podendo dar vigor àquilo que faz. Isso porque "os acontecimentos não existem sobre a linha reta do cabo desenrolado (Aion), da mesma maneira que as causas na circunferência do cabo enrolado (Chronos)" (DELEUZE, 2011, p. 147).

"Aion opõe-se a Chronos, que designa o tempo cronológico ou sucessivo, em que o antes se ordena ao depois sob a condição de um presente englobante no qual, como se diz, tudo acontece" [...] (ZOURABICHVILI, 2004, p. 11). A analogia feita por Deleuze (2011) demonstra que o acontecimento não segue uma ordem cronológica. Ele se situa justamente entre um espaço e outro do tempo, não sendo nem passado, nem presente e nem futuro; é batizado também como "entretempo" (ZOURABICHVILI, 2004, p. 11). É neste entretempo e nos sentidos dados a ele que se pode individualizar o modo como as pessoas se relacionam com o mundo, particularizando também as formas de se interpretar os eventos formativos e as aprendizagens deles decorrentes. “Nesse nível, o acontecimento não é mais apenas a diferença das coisas ou dos estados de coisas; ele afeta a subjetividade, insere a diferença no próprio sujeito" (ZOURABICHVILI, 2004, p. 11-12).

Inspirado numa concepção foucaultiana, "as ofertas universais e normativas, há muito difundidas pelos fundamentos do pensamento ocidental, não são mais suficientes para assegurar ações práticas que concebam e respeitem a subjetividade e finitude de cada sujeito", como assevera Carvalho (2010, p. 29). No que diz respeito à formação continuada de professores, estamos tão acostumados a entendê-la a partir de um planejamento que segue um cronograma bem-específico e um roteiro formativo pré-estabelecido, como aqueles pelos quais frequentemente nos submetemos, os eventos - estes tão incorporados à cultura formativa que já não nos damos conta de problematizá-los - que corroboramos esse modelo.

Subordinamo-nos a esse padrão formativo, fortemente baseado numa "herança cartesiana" (CARVALHO, 2010, p. 30), por acreditarmos que são momentos significativos de aprendizagens, e, de fato, podem ser, desde que essa organização prévia possibilite a formulação de perguntas que potencializem o pensar. "Ao elaborar a categoria de acontecimento, Deleuze expõe então o laço primordial do tempo e do sentido, ou seja, que 
uma cronologia em geral só é pensável em função de um horizonte de sentido comum as suas partes" (ZOURABICHVILI, 2004, p. 12). A partir desse movimento, o que se quer circula em torno da intencionalidade de "afastar o nevoeiro de universalidade que rodeia cada pedagogia, restabelecer o momento da originalidade do pensar" (CORAZZA, 2007a, p. 17).

A vida significa potência, movimento e o artigo indefinido é a marca do que é, a uma só vez, impessoal e singular. O indefinido sinaliza uma vida qualquer e, no entanto, esta e nenhuma outra vida: a indeterminação individual e a determinação singular. Uma vida imanente, cheia de acontecimentos, singularidades também em movimento, que atravessam os indivíduos. A ontologia tem mais afinidade com a geografia do que com a história. É mais uma questão de mapas, deslocamentos, regiões, territórios, segmentos e linhas do que de cronologias (KOHAN, 2002, p. 126).

Tem-se compreendido, a partir desta experiência de pesquisa e também desde as vivências como docente, que a formação continuada de professores tem sido mais baseada em cronologias e em concepções lineares da história dos sujeitos e dos modos como se desenvolvem profissionalmente do que em territórios construídos com os mapas, com os deslocamentos que movimentam a constituição desses sujeitos e a relação que estabelecem com o lugar. "A educação parece habitar uma ontologia contrária, na contramão desta ontologia deleuziana da imanência, do movimento, do singular não individual, da potência, do acontecimento" (KOHAN, 2002, p. 126).

A FCP, quando pautada pela busca de um padrão de sociedade, de instituição educativa e, consequentemente, de professor(a), age como se pudesse haver a possibilidade de alguém ser "o Professor-Primordial (Uno, Padrão, Verdadeiro, Normal), a partir do qual todos os professores fossem formados" (CORAZZA, 2007a, p. 4), agindo também na busca por um(a) aluno(a) ideal que atenda aos estímulos, de forma que possa vir a superar as expectativas sociais, culturais e políticas que dele são esperadas.

Esse contexto social tem gerado um clima de intolerância às diferenças de qualquer ordem, de individualismo e de competitividade. As instituições 
educativas refletem esse contexto cultural que nada mais é do que o produto de construções históricas pautadas num discurso de "normalidade". Este discurso de "normalidade" mostra-se intolerante a condutas que fogem aos padrões formatados por uma cultura que prima pela "igualdade", justamente por não tolerar a diferença. "Numa vida de singularidades e acontecimentos, importa pensar a diferença em si mesma, e resistir ao que se impõe como imagem de um pensamento dual, sem vida" (KOHAN, 2002, p. 126). Pensamos que a luta não é pela busca de uma suposta "igualdade", mas pelo respeito a toda e qualquer diferença; como afirma Kohan (2002, p. 126): "pensar a diferença em si mesma significa não conceber a diferença como diferença 'com respeito a' qualquer coisa ou diferença 'em' qualquer coisa, mas diferença enquanto diferença, enquanto intensidade, potência".

A diferença não pode ser vista do ponto de vista da aceitação ou da investida por um sentimento de compaixão. Esse tipo de relação reproduz a exclusão que contemporaneamente está revestida por um discurso de inclusão e de aceitação, porém, continuamos na busca incessante por um padrão de conduta pessoal e profissional estereotipado. Pensar a diferença enquanto diferença "significa pensar a diferença como acontecimento do pensar, como aquilo instaurado por um pensamento indócil, potente, singular" (KOHAN, 2002, p. 126).

A formação continuada de professores pode ser investida por essa potência singular do pensar: “ocorre que o pensar não está dado e há que o produzir" (KOHAN, 2002, p. 127). Produzir esse pensar é uma das condições para que a FCP seja reconduzida ao lugar que lhe é peculiar, processo contínuo de formação, espaço-tempo para aprender na relação consigo e com os outros; formação continuada de professores como eventos problematizadores, eventos encorajadores e incitadores do pensar, como eventos-acontecimentos.

O acontecimento não é o que acontece (acidente), ele é no que acontece o puro expresso que nos dá sinal e nos espera. [...] Ele é o que deve ser compreendido, o que deve ser querido, o que deve ser representado no que acontece. [...] Tornar-se digno daquilo que nos ocorre, por conseguinte, querer e capturar o acontecimento, tornar-se o filho de seus próprios acontecimentos e por aí renascer, refazer para si mesmo um nascimento, romper 
com seu nascimento de carne. Filho de seus acontecimentos e não mais de suas obras, pois a própria obra não é produzida senão pelo filho do acontecimento (DELEUZE, 2011, p. 152).

A partir dessa concepção de acontecimento, é possível sustentar que não é o evento em si que forma ou que transforma a maneira pela qual os sujeitos professores(as) pensam os contextos em que trabalham e a área em que atuam, mas o que esse movimento formativo causa neles, quais impactos e quais encontros possibilitam. Os eventos de formação continuada de professores são uma ponte para que a obra seja produzida; mas, para isso, é necessário que os sujeitos-professores(as) que participam desses eventos-acontecimentos se tornem dignos do que neles ocorre, ou seja, que participem com toda sua potência de vida. "Sem nada de acontecimento e sem nada de vida" (KOHAN, 2002, p. 128) não há formação continuada de professores que se sustente, não há produção de obras que supere ou mesmo que rompa "a imagem dogmática do pensamento que afirma um modelo, a recognição" (KOHAN, 2002, p. 127).

"A que pensar sem esta imagem, contra essa imagem dogmática: sem representação, contra o modelo, para além da proposição. Pensar é experimentar, problematizar, encontrar" (KOHAN, 2002, p. 128). A formação continuada de professores pode estar possibilitando um movimento formativo que caminhe nessa direção, que seja responsável por desconstruir a imagem dogmática que, ao longo dos tempos, foi sendo cristalizada e reproduzida. Esse movimento do pensar pode ganhar espaço na formação continuada de professores, configurada como acontecimento. Este não se trata apenas de "fatos educacionais, dados históricos, práticas pedagógicas, embora ele não exista fora dessas efetuações, só que, nelas em seu existir atual, o Acontecimento não se esgota, porque é imaterial, incorporal e virtual" (CORAZZA, 2007a, p. 4).

O acontecimento é aquilo que circula entretempos; não é palpável e nem previsível, porque está em movimento, num movimento que envolve o pensar. Um pensar transformador. É o momento em que as singularidades encontram espaços-tempos nos eventos, o que possibilita um olhar diferente, um sentir diferente, um perguntar diferente. "Pensar 
na imanência, sobre planos igualmente traçados, inventados, planos sempre móveis, mutantes. Pensar cada vez o que significa pensar. Pensar os problemas, as soluções, os sentidos, as verdades, a diferença" (KOHAN, 2002, p. 128). Os conhecimentos produzidos a partir desse processo tornam-se impenetráveis aos olhos de outros porque têm como característica a autenticidade do pensar. Um pensar "sem pontos fixos, sem quietude. Nunca parar de pensar. Nunca parar o pensar. Movimento do pensar. Nomadismo do pensar. Singularidade do pensar" (KOHAN, 2002, p. 128).

A formação continuada de professores pensada nessa perspectiva potencializa o pensar, estabelecendo linhas de fugas que visam romper a ideia de "Professor - Modelo" (CORAZZA, 2007a, p. 4) e, porque não dizer, de formação-modelo, "dotada de uma qualidade essencial [...] à qual um e todos os professores deverão submeter-se ou se esforçarem para dela se aproximarem, como Cópias bem ou mal assemelhadas" (CORAZZA, 2007a, p. 5). Por se acreditar na possibilidade de que a formação continuada de professores pode ir muito além dessa reprodução é que incide sobre este trabalho a preocupação de que se possa garantir que os sujeitos-professores "sejam dignos dos Acontecimentos e que os professores artistem a Educação - tudo isso em devir revolucionário. Único devir que conjura o intolerável e nos faz voltar a acreditar no mundo" (CORAZZA, 2007a, p. 18).

Michael Foucault transitou pelo conceito de acontecimento. Cabe ressaltar aqui a compreensão dele, pois corrobora e acrescenta às considerações já destacadas em Deleuze (2011). Na obra O governo de si e dos outros (2010b), em que são publicados os seminários realizados por Foucault no Collège de France entre os anos de 1982 e 1983, o conceito de acontecimento é tratado por Foucault tendo como base analítica a Revolução, no caso, a Revolução Francesa, considerada por ele um acontecimento "ruidoso, manifesto. [...] Que faz com que o que era grande fique pequeno e o que era pequeno fique grande, e que abole e engole as estruturas mais sólidas" (FOUCAULT, 2010, p. 18). Com base na afirmação de $\mathrm{Kant}^{4}$ de que "não é a revolução em si que faz

4 Filósofo alemão, considerado por muitos estudiosos o pensador mais influente da Idade Moderna. 
sentido" (FOUCAULT, 2010, p. 18), problematiza a ideia de que não é o fato em si que é significativo, mas o efeito que ele causa; esse efeito é que pode gerar mudanças.

Foucault (2010, p. 18) chama a atenção para o fato de que "não é nos grandes acontecimentos que devemos buscar esse sinal que é rememorativo, demonstrativo e prognóstico do progresso. É em acontecimentos quase imperceptíveis". Sendo assim, é possível afirmar que não são apenas os eventos formativos formais que possibilitam aprendizagens, mas, na informalidade do cotidiano, é possível que se aprenda. De acordo com Gallo (2007, p. 24), “o acontecimento-cotidiano é tudo aquilo que escapa de nosso planejamento, seja como professores/ as, como gestores do processo educacional, como funcionários da instituição escolar, seja como pais, [...] esses acontecimentos são potencialmente situações formativas". É nesse sentido que um olhar estético ao cotidiano pode transformar os modos de existir docente. Esse movimento pode ser potencializado pelos processos de formação continuada de professores(as).

\section{Formação continuada de professores como acontecimento}

Por mais significativos e bem-organizados que possam ser os eventos formais de formação continuada de professores, apenas com base nessas experiências, que podem ser grandiosas, a formação continuada de professores efetivamente pode não conduzir à aprendizagem que dela se espera. "O importante, o que faz sentido e o que vai constituir o sinal do progresso, [...] o fator significativo é o entusiasmo pela Revolução" (FOUCAULT, 2010, p. 19). Operando com base nessa compreensão foucaultiana, entendemos que não é apenas o evento formal de formação continuada em si que possibilita a aprendizagem docente, mas também os modos como esses acontecimentos formativos afetam os sujeitos,

Tem a pedra angular de sua filosofia exposta na obra Crítica da Razão Pura (1781). Nela, o filósofo examina as bases do conhecimento humano e cria uma epistemologia individual. Em Metafísica da Ética (1797), expõe seu sistema ético, firmado na liberdade fundamental do indivíduo e na ideia de que a razão é a autoridade última da moral. Além de seus trabalhos sobre filosofia, produziu tratados sobre diversas matérias científicas, sobretudo na área da geografia física, em que se destaca sua História Universal da Natureza e Teoria Celeste (1755) (FONTANELLA, 2004). 
o que causam nos sujeitos-professores e como esses eventos formais podem adentrar o cotidiano das práticas pedagógicas transformando-as e atribuindo-lhes outros e, talvez, novos sentidos. Essa ressignificação se faz premente, pois o cenário cotidiano, a dinâmica da vida e do conhecimento demandam outras estratégias formativas que superem os modelos anacrônicos que têm sido adotados. No entender de Marin (1995), não é mais possível, hoje, pensar no processo formativo como aquele conjunto de ações capaz de completar alguém, de torná-lo perfeito, de concluí-lo, sob a pena de negar a raiz da própria educação, ou seja, a ideia da educabilidade do ser humano.

As compreensões formuladas a partir deste estudo partem do princípio de que a formação continuada de professores, amparada pelo conceito de acontecimento, pode possibilitar que se acredite nesse processo formativo como um movimento potencializador do pensar que mobilize os sujeitosprofessores a produzirem conhecimentos e a criarem outras/novas possibilidades de exercício da prática docente. Um movimento que desloca a ideia de formação continuada vinculada a um espaço de transferência de padrões, de ideias, de fórmula para um espaço em que se privilegia o ato criativo. As instituições educativas, os planejamentos das aulas, as práticas pedagógicas e o cotidiano docente, de modo geral, ganham outros tons, ganham cor e vida. A formação continuada de professores pensada dessa maneira contribui para que o cotidiano das práticas educativas, bem como a relação estabelecida com os processos de ensinar e de aprender, passe a ser menos rotineiro, porque refuta a repetição e as cópias que obscurecem o ato criativo.

A formação continuada de professores articulada com o conceito de acontecimento contribui para que a originalidade e a autenticidade do pensar sejam marcas que passem a constituir os sujeitos-professores; estes considerados em sua singularidade e efetivamente comprometidos com o ato-evento formativo. A FCP pensada a partir do conceito de acontecimento envolve também os processos de aprendizagem docente que nem sempre estão protocolados, estruturados cronologicamente e planejados previamente; admite que o processo formativo continuado ultrapasse os limites da linearidade do tempo e do espaço porque flutua 
entre eles, ou seja, situa-se entretempos.

Eventos e acontecimentos não estão sendo entendidos dicotomicamente, mas como jogos de forças, um implicado no outro, espaço "liso e estriado" (DELEUZE; GUATTARI, 2012). O espaço estriado é o da normatização, da regulamentação, o que pode ser denominado como gestão-macro da educação; liso é o espaço que envolve diretamente os sujeitos, o que pode ser definido como gestão-micro, ou seja, os sujeitos-professores inseridos em uma instituição educativa.

Ao campo da macropolítica, cabe gestar e gerir, controlar; aquilo que Deleuze e Guattari chamaram, em Mil Platôs (2012), de “estriamento do espaço, isto é, a definição de regras, protocolos, formas de ação, que permitem controlar todo o processo" (apud GALLO, 2007, p. 28). Esses são alguns dos propósitos expressos pela legislação que regulamenta a formação continuada de professores, e são também os "propósitos e os efeitos de ações como as dos Parâmetros e Diretrizes Curriculares, dos Planos Decenais de Educação, dos Projetos Político-Pedagógicos das escolas" (GALLO, 2007, p. 28). A legislação, de modo geral, tem a intencionalidade de propor formas de gestar os processos formativos e de, por meio de mecanismos avaliativos, controlar seus efeitos. A objetividade é uma de suas características.

Já no campo da micropolítica, a educação opera mais pelo alisamento do espaço, permitindo o livre-fluxo da criação; aqui, o acontecimento pode ter lugar. "É por isso que, embora não haja oposição entre o espaço liso e estriado, não raro a micropolítica constitui-se como espaço de resistência aos atos da macropolítica" (GALLO, 2007, p. 28-29). É nesse sentido que os sujeitos-professores podem ser investidos de potência, porque, como afirma Foucault: “Lá onde há poder há resistência [...] estes pontos de resistências estão presentes em toda rede de poder" (FOUCAULT, 2004, p. 91). Isso faz emergir algumas possibilidades de ações e de intervenções formativas e pedagógicas que podem partir dos próprios sujeitos-professores, desde que haja, por parte dos(as) docentes, uma apropriação dessa relação, desses jogos de forças e de resistências que constituem o exercício da profissão: “A micropolítica pode ser capturada pela macropolítica e ser estratificada, estriada, engessada. Mas 
o cotidiano opera na ordem do acontecimento, isto é, do inesperado e do inusitado, as fugas sempre acontecem e o estriamento nunca consegue ser total e absoluto" (GALLO, 2007, p. 28-29). O autor completa seu raciocínio ao afirmar que, para

[...] resistir, é importante abrir-se ao acontecimento. Estar atento àquilo que ocorre no cotidiano da escola, a fim de potencializá-lo criativamente, e não ser tragado, engolido pelo acontecimento. Perder-se no acontecimento, não conseguindo produzir, é tão ruim quanto estratificá-lo, fazê-lo perder a potência, dominando os fluxos e reenquadrando as diferenças na norma. [...]. Resistir e criar. Essas são as possibilidades que nos abre o cotidiano da escola, quando escolhemos agir no fluxo dos acontecimentos (GALLO, 2007, p. 39).

Escolher seguir o fluxo dos acontecimentos não significa se dobrar a ele sem estabelecer uma relação crítica e criativa, amparada por fundamentos teórico-conceituais que sustentem as práticas pedagógicas que são desenvolvidas nas instituições educativas. Exige profundo conhecimento e sabedoria. Amparada pelo pensamento de Foucault, Corazza (2007a) pondera: "o ato de conhecer e saber é de grande solidão, pois não importa o que se ensine a alguém, o estimulante é o que esse alguém consegue criar - e não reproduzir - a partir do que experienciou (leituras, aulas, interlocuções com outros [...]) " (CORAZZA, 2007a, p. 18). Essa relação com o conhecimento e com o saber é que pode dar outros sentidos e possibilitar que "os sujeitos-professores artistem" em educação.

Dar lugar para a diferença e para o diferente, o qual espera aquilo que não se repete, o que não é costumeiro. Somente aqui é possível produzir abalos, provocar mudanças no que somos capazes de ver e de dizer, dar alegres cambalhotas, radicalizar nossas relações com o poder e com o saber, partir as linhas, mudar de orientação, desenhar novas paisagens, promover outras fulgurações. Esse movimento se completa num circuito que se inicia com o querer mudar; em seguida, buscar problematizar nossa prática para enxergar onde precisamos mudar; e, por fim, buscar formação para que possamos melhor desenvolver e nutrir nosso fazer. Enfim, artistar, inventando novos estilos de vida e, portanto, 
de práticas formativas e pedagógicas (CORAZZA, 2007b), fazendo da formação continuada um processo de desenvolvimento profissional de professores(as) que dê vazão a um existir como evento.

Eventos e acontecimentos são compreendidos como situações que podem constituir-se em experiências formativas, cada uma operando e se desenvolvendo de forma diferente, mas tendo a intencionalidade de criar condições para se pensar sobre a docência, pensar-se como docente e pensar na relação que se estabelece com os alunos, o que, na perspectiva desta análise, pode ser importante para a produção de outros5 sentidos e de outros motivos6.

\section{Considerações finais}

Nem tudo pode ser prescrito antecipadamente. A formação continuada pode ser pensada como acontecimento justamente por entender que o que esse processo tem de formativo pode ultrapassar os limites daquilo que é ou que está protocolado. O que cada pessoa faz com o que ouve, por exemplo, como sente o que ouve, quais movimentos indagativos e analíticos podem provocar, tem um caráter que foge um pouco daquilo que é normativo. Segundo Marin (1995), os profissionais da educação não podem e não devem ser persuadidos ou convencidos de ideias; eles devem conhecê-las, analisá-las, criticá-las e até mesmo aceitá-las, mas mediante o uso da razão.

A partir dessa perspectiva analítica, criam-se possibilidades de se questionar modelos de formação que têm como característica a verticalização, com horários fixos, momentos únicos e lineares para a realização das práticas de formação continuada. A formação continuada, sendo pensada como acontecimento, propõe a horizontalização das formações, ou seja, a se entender que a verticalização é importante, que

5 Digo outros porque nem sempre esse movimento cria novos sentidos, mas pode fazer perceber outras formas de se compreender a realidade, a formação, a vida etc., sem que, necessariamente, represente a essência de algo que nunca existiu até então. O que problematizo é a possibilidade de se desenvolver outros modos de existir, e não novos modos de ser. O ser é o sujeito-professor(a), porém, seu modo de existir como docente é que ganha outros contornos, outros sentidos.

6 De acordo com Libâneo, "motivos são as razões que as pessoas dão a si mesmas, para fazer o que fazem e pensar o que pensam" (LIBÂNEO, 2013, p. 15). 
determinar pessoas, espaços e horários para a realização de eventos de formação continuada é necessário; além disso, porém, é fundamental que as instituições e as pessoas que nelas atuam estejam abertas para aprenderem a partir das indagações e das surpresas que o cotidiano pode revelar.

Para que seja possível esse redimensionamento teórico-conceitual acerca da formação continuada de professores, é necessário um envolvimento ético e estético ${ }^{7}$ com a profissão. De acordo com Hermann (2005), "pela educação e cultura, o homem constitui uma segunda natureza que não é apenas ética - enquanto torna-se criador de leis e costumes, mas também estética - enquanto produz uma realidade, uma natureza de produto como conhecemos na arte" (HERMANN, 2005, p. 10). Envolvido por esse conceito, o processo de formação continuada opera com as leis, com as normas, com os critérios, com as posturas ética, mas também produz culturas e transforma realidades - e com a estética. Um movimento que tem potencialidades para produzir outros modos de ser docente.

O cotidiano das instituições educativas, nos diferentes níveis de ensino, também pode ser considerado como eventos, porém com uma concepção menos prescritiva, pois dá vazão ao desenvolvimento de uma estética do cotidiano.

A estética do cotidiano subentende, além dos objetos ou atividades presentes na vida comum, considerados possuidores de valor estético por aquela cultura, também e principalmente a subjetividade dos sujeitos que a compõem e cuja estética se organiza a partir de múltiplas facetas do seu processo de vida e de transformação (RICHTER, 2003, p. 21).

7 Corroboro o entendimento de Hermann (2005, p. 35) ao afirmar que o "retorno triunfante" da estética, no mundo contemporâneo, como um modo de lidar com a pluralidade e com uma realidade de finalidade aberta, traz consigo os processos de estetização da realidade enquanto mero ornamento. $O$ que se percebe é que o estético se alojou no pensamento contemporâneo como uma estetização geral da vida, na medida em que acentuou o aspecto efêmero, transitório da produção artística. Vivemos numa sociedade de cultura de massas, em que a informação, a cultura e o entretenimento difundidos pelos meios de comunicação adquiriram um peso muito significativo, pois constituem uma esfera pública de consensos, de sentimentos e de gosto comum. Ou seja, estamos numa sociedade na qual a estetização passou a definir nossas relações com a realidade. O que se pretende sublinhar aqui como o caráter produtivo do estético não se confunde com certa estetização da ética das sociedades contemporâneas, em que o cotidiano está impregnado pela preocupação com o glamour, a satisfação da aparência pessoal. Nesse âmbito, o reconhecimento do outro e a preocupação com os danos que nossas ações podem causar são deixados de lado, em favor de um individualismo exacerbado. 
Pereira (1996, p. 85) desenvolve o que chama de uma "tentativa de ressignificação" da estética que, de acordo com Richter, "pode ser muito útil para o estudo sobre a estética do cotidiano" (RITCHER, 2003, p. 21). O autor busca resgatar uma "diferença dentro da estética" que estabeleça as designações de "macroestética" e de "microestética". A macroestética refere-se a uma Estética com "E" maiúsculo, que nasce no século XVIII como campo epistemológico independente, como disciplina. Já a microestética "se refere ao modo como cada indivíduo se organiza enquanto subjetividade; é a ordem da processualidade, dos campos interativos de forças vivas da exterioridade atravessando um sujeitoem-prática" (RICHTER, 2003, p. 21). Dito de outra forma:

A primeira (macroestética) é produto de uma subjetividade que quer se instituir como modelo homogeneizante (por exemplo, nos conceitos de belo, de criatividade), enquanto a segunda (microestética) é processo de produção de subjetividades. Dessa forma, a estética tem a ver com a maneira pela qual o mundo toma sentido para nós, de acordo com a maneira pela qual nos afeta e pela qual nós a afetamos. (PEREIRA, 1996, p. 127).

Quando tratam da microestética, Pereira (1996) e Richter (2003) consideram os modos diferentes pelos quais os sujeitos habitam o mundo; no caso desta pesquisa, os modos pelos quais os sujeitos-professores se relacionam com a sua formação e com a sua profissão. Modos únicos e irrepetíveis de ser e de estar professor(a). Entendemos que a formação continuada de professores pode operar a partir dessa lógica, instigando os sujeitos-professores a olharem com mais cuidado para seus modos de constituição e, assim, a darem espaço para que o cotidiano seja visto como um espaço-tempo privilegiado de formação. Ser afetado pelo cotidiano, de modo que ele possa nos ensinar conteúdos-sentidos que nem sempre estão prescritos em manuais, em normas, em espaços formais instituídos como lugares de formação continuada. Esta adquiriria a prerrogativa atribuída por Severino (2006) ao referir-se à formação, ou seja, como um processo de devir humanizador, no qual o ser natural devém pessoa, ou seja, ser cultural. Tal sentido encontra sua maior riqueza nas operações do verbo reflexivo, numa indicação de que o próprio sujeito é agente 
responsável pela sua construção.

Para tanto, é necessário dar atenção à diversidade de acontecimentos de todos os gêneros que constituem os espaços-tempos educativos e, por isso mesmo, que tornam possíveis aprendizagens difíceis de se planejar antecipadamente. Observamos que os conteúdos específicos das áreas em que os docentes atuam são as bases que orientam o desenvolvimento das aulas e são as ferramentas com as quais os professores desenvolvem seu trabalho; portanto, imprescindíveis para qualquer docente. Ressaltamos que este trabalho considera fundamental o planejamento diário feito pelos(as) docentes. Esse é decisivo, pois tem como objetivos elencar prioridades e organizar a rotina, os conteúdos e a forma pela qual a aula será desenvolvida. Esse aspecto formal que fundamenta a prática docente pode estar articulado com outros aspectos que são eventuais: os acontecimentos. "Não se perguntará qual o sentido de acontecimento: o acontecimento é o próprio sentido [...]" (ZOURABICHVILI, 2004, p. 6).

Nessa perspectiva é que o acontecimento pode também ser formativo, porque o que acontece tem sentido e pode ensinar algo ou alguma coisa; no caso da docência, transcende a relação com o conteúdo, que é condição sine qua non para o exercício da docência, tendo potencialidades para atingir também as relações interpessoais e os aspectos emocionais e afetivos que estão vinculados à prática pedagógica. "O acontecimento é inseparavelmente o sentido das frases e o devir do mundo; é o que, do mundo, deixa-se envolver na linguagem e permite que funcione. Assim, o conceito de acontecimento é exposto numa lógica do sentido" (ZOURABICHVILI, 2004, p. 7).

Então, deve-se perguntar: quais são os sentidos? Toda e qualquer ação formativa pode partir desse questionamento, mas é uma questão que cada sujeito-professor pode fazer a si próprio quando faz sua inscrição para a participação em um evento de formação continuada, quando faz sua matrícula num curso de pós-graduação, ou ainda quando dá entrada em seu local de trabalho, no momento em que seleciona os conteúdos que trabalhará com os alunos, ao planejar as aulas e, principalmente, no instante em que entra na sala de aula para o momento único e singular que é a concretização da aula. O processo de formação de professores 
antecede, mas também se confunde com a aula; as subjetividades que aí circulam podem ter caráter formativo, e todo esse movimento de ir e vir docente pode ser pensado como estética do cotidiano.

\section{Referências}

CARVALHO, A. F. de. Foucault e a função-educador: sujeição e experiências de subjetividades ativas na formação humana. Ijuí: Unijuí, 2010.

CORAZZA, S. M. Labirintos da pesquisa, diante dos ferrolhos. In: COSTA, Marisa Vorraber (Org.). Caminhos investigativos I: novos olhares na pesquisa em educação. Rio de Janeiro: Lamparina Editora, 2007a.

. Educação por Deleuze. Para pensar, pesquisar e artistar a educação: sem ensaio não há inspiração. Revista Educação, São Paulo, n. 6, p. 68-73, 2007b.

DELEUZE, G. Lógica do sentido. São Paulo: Perspectiva, 2011.

DELEUZE, G.; GUATTARI, F. Mil Platôs: capitalismo e esquizofrenia. 2. ed. São Paulo: Editora 34, 2011.

Mil Platôs: capitalismos e esquizofrenia 2. ed. São Paulo: Editora $34,2012$.

FONTANELLA, F. C. Prefácio sobre a obra de Kant. In: KANT, I. Sobre a pedagogia. Piracicaba: Unimep, 2004.

FOUCAULT, M. O governo de si e dos outros. São Paulo: Martins Fontes, 2010.

. Vigiar e punir. Petrópolis, RJ: Vozes, 2004.

GALLO, S. Acontecimento e resistência: educação menor no cotidiano da 
escola. In: CAMARGO, A. M. F. de; MARIGUELA, M. (Orgs.). Cotidiano escolar: emergência e invenção. Piracicaba, SP: Jacintha Editores, 2007. p. 21-39.

GIRALDI, J. W. A aula como acontecimento. São Carlos, SP: Pedro e João Editores, 2010.

HERMANN, N. Ética e estética: a relação quase esquecida. Porto Alegre: Edipucs, 2005.

KOHAN, W. O. Entre Deleuze e a Educação: notas para uma política do pensamento. Educação e Realidade, Porto Alegre, v. 27, n. 2, p. 123-130, jul./dez. 2002.

LIBÂNEO, J. C. Internacionalização das políticas educacionais e repercussões no funcionamento curricular e pedagógico das escolas. In: LIBÂNEO, J.; SUANNO, M.; LIMONTA, S. (Orgs.). Qualidade da escola pública: políticas educacionais, didática e formação de professores. Goiânia: Ceped, 2013. p. 47-72.

MARIN, A. J. Educação continuada: introdução a uma análise de termos e concepções. Cadernos CEDES, Campinas, SP, n. 36, p. 13-20, jan./1995.

NOGARO, A.SILVA, H. A. da. Professor reflexivo: prática emancipatória? Curitiba: CRV, 2015.

PEREIRA, M. V. A estética da professoralidade. Um estudo interdisciplinar sobre a subjetividade do professor. 1996. 297 f. Tese (Doutorado em Educação) - Pontifícia Universidade Católica de São Paulo, São Paulo, 1996.

RICHTER, I. M. Interculturalidade e estética do cotidiano no ensino das artes. Campinas, SP: Mercado das Letras, 2003.

SEVERINO, A. J. A busca do sentido da formação humana: tarefa da filosofia da educação. Educação e Pesquisa, São Paulo, v. 32, n 3, p. 
619-634, set./dez. 2006.

ZOURABICHVILI, F. O vocabulário de Deleuze. Rio de Janeiro: Centro Interdisciplinar de Estudo em Novas Tecnologias; Campinas, SP: Unicamp, 2004. 